\title{
Technology: A Necessary but Not Sufficient Condition for Future Personal Mobility
}

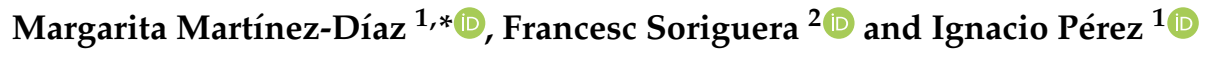 \\ 1 School of Civil Engineering, Campus de Elviña, University of A Coruña, s/n, 15071 A Coruña, Spain; \\ ignacio.perez1@udc.es \\ 2 Barcelona Innovative Transportation (BIT), UPC-BarcelonaTech, Jordi Girona 1-3, 08034 Barcelona, Spain; \\ francesc.soriguera@upc.edu \\ * Correspondence: margarita.martinez@udc.es; Tel.: +34-881-016-031
}

Received: 28 September 2018; Accepted: 7 November 2018; Published: 11 November 2018

\begin{abstract}
Technological advances revolutionize industrial processes, science, communications, and our way of life. However, developed societies have reached a stage in which the fascination with technological innovations often results in their indiscriminate consumption. In this paper, road traffic is used as a line of argument to demonstrate that the random introduction of technology does not imply benefits to society. Particularly, it is analyzed why some of the potential benefits of technological progress are lost in fields such as traffic monitoring, data handling, and traffic management, or in sustainable mobility initiatives, such as the introduction of electric vehicles or the implementation vehicle sharing projects. The risks faced in the future advent of autonomous vehicles are also discussed, and ideas for improvement suggested. A critical reflection on other transportation modes that are expected to be realized in the near future is included as well. The performed analysis evidences that the potential improvement in personal mobility will not become a reality if it exclusively relies on the latest technological devices, in line with consumers' fantasies or economic interests. This is a statement that could be generalized to many other fields. The implementation/consumption of a particular technology should not be an objective in itself, but a tool to bring benefits to society.
\end{abstract}

Keywords: future personal mobility; sustainable mobility; society-oriented mobility; technological advances; technology overconsumption; trade-off analysis

\section{Introduction}

The Mars Climate Orbiter disintegrated in 1999 after its trajectory passed too close to Mars' atmosphere. The error in the trajectory was due to the misuse of non-SI units in the part of the software that guided the robotic space probe [1]. More recently, in 2016, the driver of a Tesla Model S died in Florida (USA) after crashing into a truck. The Autopilot sensors of the car failed to distinguish a white tractor-trailer crossing the highway against the bright white sky. Another driver of a Tesla Model X driving in Autopilot mode died in 2018 when the vehicle crashed into a concrete lane divider on a Californian freeway (USA) without any apparent reason; no pre-crash braking, and no evasive steering movement was detected immediately before the collision. However, the driver had received visual and audible hands-on warnings, and his hands had been detected on the wheel $1 \mathrm{~min}$ before the accident. Some days before in Arizona (USA), a self-driving car property of Uber ran over a woman who had suddenly attempted to cross the road just in front of it. The investigation concluded that the vehicle detected her, but classified her as a "false positive", as if she were, for example, a plastic bag.

Technological advances are a powerful and necessary tool for social development. The high level of scientific investigation all over the world makes it possible for new inventions, gadgets, and software 
to come to light every day. Moreover, those with a disruptive potential can even change the rules of society, people's behavior, and, ultimately, the way people perceive life [2]. Nevertheless, there is a tendency to consider technology as the final objective, preventing some of the social benefits from materializing. This is not only a problem of individuals being addicted to technology, but also of companies and administrations randomly consuming and implementing it. The above-mentioned incidents are, admittedly, extreme examples. However, they are used to draw attention towards one fact: we cannot simply focus on the allure of technology; we must work to make the most of its potential, developing the adequate context for its proper usage. Additionally, it is necessary to maintain a comprehensive standpoint of the social purposes of its application. Usually, this has little to do with the technology itself, but with the fundamental knowledge of their field of application. This is not an easy task, considering the growing tendency to accept technological advances thoughtlessly. In this regard, advertising, sci-fi books and films have had much influence. The close link among fiction, technology, and innovation is indisputable [3]. Economic interests also play a key role, and the trained incapacity of consumers is by far the best of the consumer-goods suppliers' weapons [4]. The population is easily attracted by innovative products, and encouraged by the marketing strategies of private companies. Additionally, people tend to link technology consumption and ownership to a higher social status, and governments relate it to power and modernity.

Mobility is an important target field of technological advances, and, thus, a perfect candidate for their overconsumption. Nevertheless, from a positive point of view, mobility has continuously evolved under the influence of key industrial revolutions: the railway industry arose from the invention of the steam-powered engine, the automobile industry and popularization emerged from the birth of mass production, and Information and Communications Technology (ICT) allowed for the first steps of technology-supported travel (Bluetooth, GPS, etc.). Today, we are immersed in the so-called fourth industrial revolution, in which automobile and technology industries walk hand in hand [5]. In fact, the technological progress made by all sectors in the field of personal mobility during the last decade has been enormous. Road mobility is a clear example, with new traffic monitoring and information devices, vehicle sharing projects, electric vehicles, and cooperative or autonomous driving as the main innovations. However, congestion is still growing, and accident rates are still unsustainable. For example, an average driver in Los Angeles spent 102 peak hours in bottlenecks in 2017 [6]. The truth is that technological innovation has not had a significant impact on congestion reduction. Nevertheless, technology consumption is not a problem itself. On the contrary, it can be very beneficial if society finds the way to make the most of it. This requires a comprehensive reflection on the social goals to achieve and a deep understanding of the application field before undertaking any technological implementation. Regarding transportation and personal mobility, there exist well-founded transportation engineering principles that are aimed at reaching a sustainable system, which must prevail over any other interest.

Using road transport as a particular case study, this paper aims at warning against the danger of ignoring social needs, ethics, theoretical principles, and trade-off analyses when introducing new technologies into any relevant field for society. To that end, the pros and cons of various transport systems with high technological content are analyzed in a simple fashion. Some of them are currently used, while others are still under development (see Figure 1). The paper fills an existing gap in the literature, as it combines the results of engineering and social sciences research in the analysis, avoiding myopic approaches. The primary goal of the paper is to encourage researchers, administrations, and private companies in the transportation sector to accompany any technological advance with a comprehensive scientific research strategy that aims at the usage of technology to truly achieve an efficient, safe, inclusive, and environmentally friendly road mobility in the future. Additionally, the authors prompt traffic administrations to plan and implement technological innovations efficiently, based on their social benefit-to-cost ratio. 


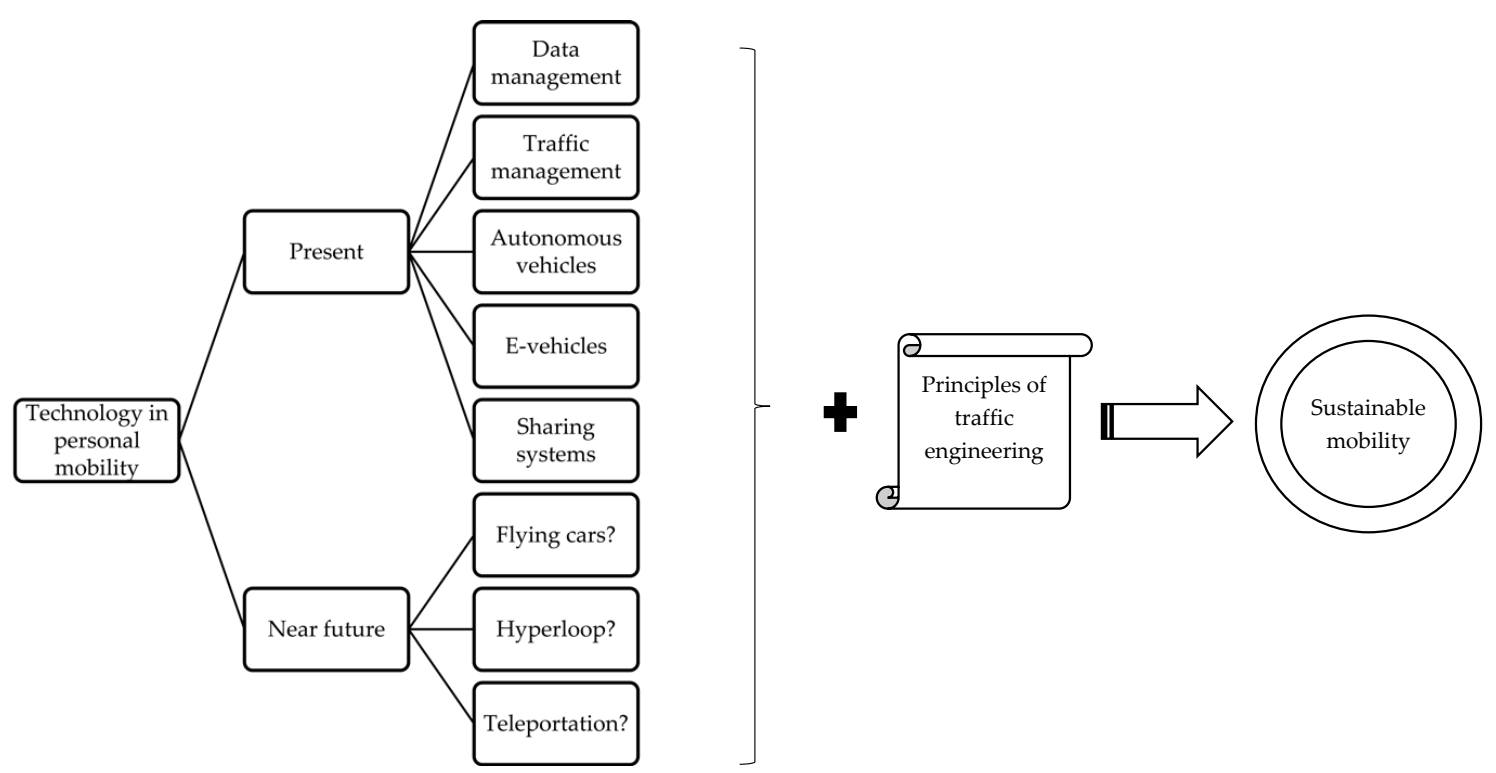

Figure 1. Technology: A necessary but not sufficient condition for future personal mobility.

\section{Scope and Methodology}

Research papers, including literature reviews, are usually written from the perspective of a single science field. However, any topic of interest can be addressed from a variety of points of view, and considerations from several standpoints enrich the discussion. Related to urban mobility, take as an example the research on the introduction of a tramway as a new mode of transportation in a particular city. Engineering papers would mainly focus on the demand, design, construction, and management of the system; papers coming from the social sciences fields would analyze people's acceptability of the new transportation mode, user preferences, and/or possible behavioral impacts; and economists would assess the economic feasibility of the new infrastructure and its consequences and impacts on the cities' economy. It is easy to realize that these three perspectives are highly related. For instance, the demand of this hypothetical tramway would depend on people's willingness to use it, and this should affect the design and management of the system in order to make it economically affordable. Many other interactions may exist. This simple example supports the idea that, at least, some cross-field reflections would be advisable in any scientific study. However, it is unavoidable that a narrow scope prevails when the topic faced is very specific. For example, when designing an algorithm to dynamically modify the initial routes of our tramway in the case of unexpected situations (e.g., incidents). In this context, the added value of the present paper is given by its singularity and broad scope when addressing the relationship between technology and personal mobility, as it combines engineering, social sciences, economic, and environmental principles to assess current and future transportation modes. Such a broad perspective avoids very detailed analyses of the topics addressed. However, this is not necessary to achieve the final goal of the paper, which additionally tries to define an adequate framework from where to build on more specific research.

The introduction of technology under efficient and sustainable principles (i.e., broadly speaking this is environmentally friendly, functional, equitable, inclusive, and economically efficient) is an ambitious objective. Many stakeholders must collaborate to achieve this final goal, ranging from academics to practitioners, from the administration to private companies ... and at the end of the day, the objective will only be fulfilled with the implication of the whole society. This is the reason why this paper is intended for a broad audience interested in personal mobility and beyond, as the underlying message is relevant for any sector with societal implications.

The selection of the particular topics and case studies that are discussed in the paper results from the authors' interests and expertise and follows the guidelines provided in [7]. In addition, special attention has been paid to select topics with wide impacts on society and with easily interpretable 
fundamental concepts, so that the main points discussed can be easily understood even by non-experts in the field.

Three main sources of information have been used to discuss the selected topics: (i) the existing literature; (ii) information gathered from in-situ visits to top research centers in the field; and (iii) information extracted from the participation of researchers in seminars, interviews, and round tables. Efforts have been devoted to analyze indexed journal papers on the topics covered. To that end, high impact journals were chosen, according to the JCR - Journal Citation Reports and SJR - Scientific Journal Rankings. Then, a Boolean search based on relevant keywords for each subject (see the present paper keywords) was performed. Taking into account the rapid evolution of technology and mobility, papers published from 2010 onwards were consulted first. Notwithstanding, previous research with a relevant impact on the field has also been considered. However, for the case of futuristic transportation modes, no or only a few articles were found. In these cases, informative sources combined with the expert criteria of the authors were used.

The structure of the remainder of the paper starts with Section 3, which discusses the current application of technology in personal mobility, highlighting the reasons that prevent us from obtaining larger benefits. After, in Section 4, the discussion moves to futuristic technologies, which are still under development, with a much higher level of uncertainty, and with an intense debate about their practical feasibility. Section 5 includes an assessment of the impacts of the considered technologies and strategies on the sustainability of personal mobility. This assessment is performed using a multicriteria analysis (MCA), which follows a hybrid methodology that is based on the Analytic Hierarchy Process (AHP) and on the Evidential Reasoning (ER) approach. AHP, as defined by Saaty [8,9], is a procedure for establishing priorities in multicriteria decision-making. Under this framework, the analyzed factors are compared under different criteria with different weights. These weights are established according to the hierarchy of their impacts on the final objectives. AHP has been proved to be a powerful tool when handling both qualitative and quantitative factors [10]. For its part, the ER approach, developed in the 1990s, is being increasingly used to develop MCA. Based on the Dempster-Shafer theory of evidence, which was first proposed by Dempster [11] and later developed by Shafer [12], it is considered a generalization of the Bayesian theory of probability that allows us to handle uncertainty, imprecision, and randomness [13]. The ER approach uses a distributed modelling framework. A belief decision matrix is constructed to assess different alternatives under different criteria, either qualitatively or quantitatively (i.e., with numerical scores) and even in contexts where the lack of evidence is noticeable. Such a matrix provides a coherent framework to make structured and robust decisions by determining each factor's relative significance for the final goal. However, the common situation when analyzing complex phenomena consists in having some empirical data that can be taken as a ground truth, other data with some uncertainty, and a lack of data regarding several inputs. In such a context, a hybrid approach in which AHP is first used to assign weights to the multiple criteria, and, second, ER is introduced to deal with uncertainty by assigning the assessment grades, turns out to be a very powerful combination. Several examples of its usefulness can be found in $[10,14,15]$. This hybrid approach has been used to perform the multicriteria analysis included in Section 5 of this paper because of (i) the complexity of the analyzed phenomena (i.e., future personal mobility) and (ii) the uncertainty regarding the assessed alternatives, especially those that are more futuristic. After the $\mathrm{MCA}$, the present paper ends with the conclusions section, and the reference list.

\section{Technology in Today's Road Mobility: What Fails? Some Examples}

The contribution of technology to road mobility is incontestable. Consider, for example, the continuous evolution of the safety mechanisms that have been introduced into vehicles. However, a poor application of technology can result in it being useless, or, at least, implies its underutilization. The following sections deal with some particular cases. 


\subsection{Data Management in Road Transportation}

The mass consumption of mobile phones, tablets, GPS navigation devices, etc. as well as the improvement of wireless communications and the introduction of new ICT in the infrastructure have completely changed the way people plan their driving. For example, drivers can receive (and provide) information concerning traffic conditions through multiple applications. In the past, drivers made their decisions intuitively and based on their experience. Today, drivers decide based on assorted and recent data. However, the question is: how does this improved scenario globally affect traffic conditions? The answer is that better information has not implied a major improvement of road mobility $[6,16]$. The English mathematician and transport analyst John Glen Wardrop (1922-1989) explained the reason for this paradox in his well-known equilibrium principles for traffic assignment. Wardrop's first principle states that if drivers have perfect information and chose freely, all used routes between two particular locations have the same cost (mainly in terms of time). Any other unused route has larger costs and it is not chosen, as each individual seeks to minimize his own cost. Wardrop [17] proved that this so-called "User Equilibrium" can be a suboptimal situation where the "selfish" drivers' decisions imply that no driver can lower his/her cost via unilateral actions or decisions. This individual way of acting prevents the road system from improving. Consider, for example, several drivers who want to reach the beach on a Sunday morning coming from the city center. They check their apps and receive more or less the same information: way A is the shortest and safest. Of course, they take it. In the middle of the trip, they receive a warning regarding an accident that had occurred few kilometers ahead, and the advice to take an alternative route B. Most drivers will change to this route, where congestion will thus gradually appear. Most apps will then propose a change to route $C$, which will subsequently become congested. This simple example shows that the use of information must be accompanied by some management strategy that is applied by a higher-level control entity.

This alternative approach in the use of information was also outlined by Wardrop [17] in his second principle. It expounds that there is a situation (the system optimal) in which the average cost across all users of the network is minimal. To achieve the system optimal situation, some drivers need to be penalized, and experience costs that are higher than their individual minimum, for the benefit of the entire system. Control implies cooperation among all drivers in the route assignment, so that the most efficient performance of the entire system is ensured. Although the idea is logical, it is not easy to convince users to behave jointly and collaboratively, especially when they could be better off individually. In everyday situations, humans tend to use their available means (in this case the information) for selfish rather than altruistic purposes [18]. Thus, the enforcement of control strategies is needed and the initiative must rely on traffic management centers, which must establish dynamic management strategies to optimize traffic performance.

In this context, data privacy will become a central issue in the management of traffic data. Although drivers are aware that many companies (e.g., Google, Inrix) collect their data while travelling, this information is generally assumed to be treated anonymously and collectively. Nevertheless, the growing concerns about data privacy will put extra pressure on individual data gathering, management, and usage. To what extent will drivers accept to share their individual data? For which purposes? Additionally, what about losing their freedom while driving in a highly controlled network? Privacy conceptions, as well as compliance with the instructions given, differ according to the age of drivers and previous knowledge of the objectives [19]. Thus, informative and educational campaigns should accompany management strategies and will be essential for their success.

Last but not least, information accuracy will even be more important in future scenarios than today, because it will strongly compromise the performance of the entire system. Accuracy is not only related to the measurement capabilities of surveillance devices but also to the methodologies used for data treatment $[20,21]$. Small details are sometimes overlooked, leading to biased results. Two particular and common examples of this kind of bad practice affect speeds and travel time information.

Speed is a fundamental parameter for traffic analysis. It is a well-known concept whose general meaning can be understood by everybody. However, the familiarity of the concept should not lead 
us to overlook the different definitions of speed that are needed in a traffic analysis, and to derive consistent information: spot speed, instantaneous speed, average speed, free flow speed, etc. In fact, the undifferentiated use of these terms is not uncommon. Macroscopic analyses, for example, work with parameters that characterize the global behavior of traffic, aggregating the variables measured from individual vehicles. Regarding speeds, there are two possible average magnitudes with different meanings. On the one hand, the space-mean speed, $\overline{v_{s}}$, is the average speed of all vehicles in a particular stretch of the roadway at a specific instant. On the other hand, the time-mean speed, $\bar{v}_{t}$, is the average speed of all vehicles that pass over a section of a road during a certain time interval. Time-mean speeds are always larger than or equal to space-mean speeds [17]. Although both are useful, most problems faced by traffic management centers require space means: they are the ones that relate flow $(q)$ and density $(k)$ (i.e., by using the fundamental equation of traffic flow), and which allow us to obtain average travel times. However, the common arithmetic average of individual speeds measured at a fixed location provides time-mean speeds. Therefore, many traffic studies use these biased time means as inputs, considering them as equivalent to space means. Consequently, inaccuracies arise in the subsequent results, for example, in travel time estimation. The problem could be solved by modifying the roadside controllers of the traffic detectors, so that they compute harmonic averages instead of arithmetic averages of individual speeds. This simple modification has been disgracefully unachievable so far. Thus, some researchers have developed mathematical algorithms to estimate space means from time means (e.g., [22-24]). Although these developments might be very useful for traffic management and could reduce investments in technology, they have been ignored so far.

The second example affects, precisely, travel time estimation. Travel time is the most valuable information for drivers in order to plan their trips, and it is a key variable for traffic administrations in order to evaluate traffic conditions. Today, travel time measurements are available from vehicle tracking technologies, whether using GPS devices (i.e., the so-called instantaneous measured travel times) or vehicle reidentification by any other means (e.g., Bluetooth detection, toll tags, automatic image recognition, or license plate recognition cameras) [25]. This last group of measurement devices leads to the so-called arrival-based or measured travel times. Usually, the average of these measurements over a given time interval (i.e., every few minutes) is directly disseminated through mobile apps, websites, etc. However, it is easy to realize that these measurements correspond to past conditions, and are not the real-time information that drivers should receive, i.e., short-term predictions [26]. Considering that the travel time between two locations can quickly vary as a result of congestion onset or dissolution episodes, precisely when information is more valuable, this approach will yield a result that is completely inaccurate and incapable of supporting future traffic management and control strategies. Making the averaging period as short as possible, aiming at averaging only the most recent information, is not a solution. In this case, vehicle samples would be small, and, thus, measurements would fluctuate and the method would be unreliable. Therefore, this is another clear example of not achieving the final objectives even using advanced technology. The situation could even be considered detrimental with respect to the situation without any travel time information, as, in the technological era, we generally consider the provided information to be an absolute truth. Only people with globally negative attitudes toward technology or who have had previous bad experiences tend to be less trusting, regardless of their age [27]. Fortunately, it is possible to predict travel times: data fusion based on traditional and new technologies stands out as a very advantageous solution in this regard (e.g., [28,29]).

Future driving scenarios will be characterized by the presence of high-level technology, which will enable the exchange and treatment of huge amounts of data in real time. However, the need to pay attention to "small" details, such as those addressed above, will remain. Furthermore, the greater the volume of data and the number of calculations to perform, the smaller the critical analysis and the attention paid to fundamental theories. So, it is probable that the problem will be gradually enlarged and transferred to all steps, from the planning to the operative management of the transportation system. To avoid this situation, the implementation of any novel process of data treatment must 
be done carefully and step-by-step, and always under a thorough approach. Only in this way will the impacts of ITS (Intelligent Transportation Systems) on consumer behavior and social practices contribute to a more sustainable mobility [30].

\subsection{Traffic Management Strategies}

Traffic management strategies must put their efforts toward increasing vehicles' cooperation with the objective of improving traffic efficiency and safety and contributing to the global optimization of the entire transportation system. Today, traffic management centers work with real-time data in order to provide drivers with updated information and recommendations every few minutes. Typically, information is disseminated through DMS (Dynamic Message Signs), although navigation applications on-board the vehicle are also popular amongst drivers. A completely different situation is expected in the future connected and autonomous driving environment. Vehicle-to-everything (V2X) communications will allow for real-time information and instructions to reach intelligent vehicles directly, without the intervention of the driver. In addition, vehicles will also act as surveillance devices and will share their computational capabilities and data in the "cloud" in order to improve traffic conditions locally. The role of traffic management centers will then be restricted to the higher network-level coordination. However, it will take quite a long time for connected vehicles to be a significant part of the fleet. Meanwhile, the old-fashioned static traffic management strategies, which can be useless or even detrimental, should evolve towards dynamic traffic management and control approaches that are adapted to the current traffic state and that use the latest technology.

Take as an example the high-occupancy-vehicle (HOV) lanes, in which only vehicles with a predefined minimum number of passengers are allowed (generally HOV $2+$ or HOV $3+$ ). They are becoming more and more common in metropolitan freeways, with the objective of increasing the vehicle occupancy and promoting collective transportation and car-pooling. However, their effectiveness depends on their configuration [31]. It has been proven that in order to maximize their benefits, HOV lanes should be ordinary lanes that turn into HOV lanes only when necessary (Figure 2a). This configuration does not require huge investments, it can be easily implemented, and provides high flexibility in the operation of the HOV lane. Additionally, as a side result, it also smoothens and improves traffic throughput in the adjacent general-purpose lanes (i.e., the so called "smoothing effect"; see [32,33]). Nevertheless, HOV lanes are sometimes built as segregated and exclusive lanes that are isolated with concrete barriers or even run on a specific infrastructure (Figure $2 b$ ). In these configurations, it is difficult to adapt the operation of HOV lanes to different traffic conditions due to the limited spatial accessibility.

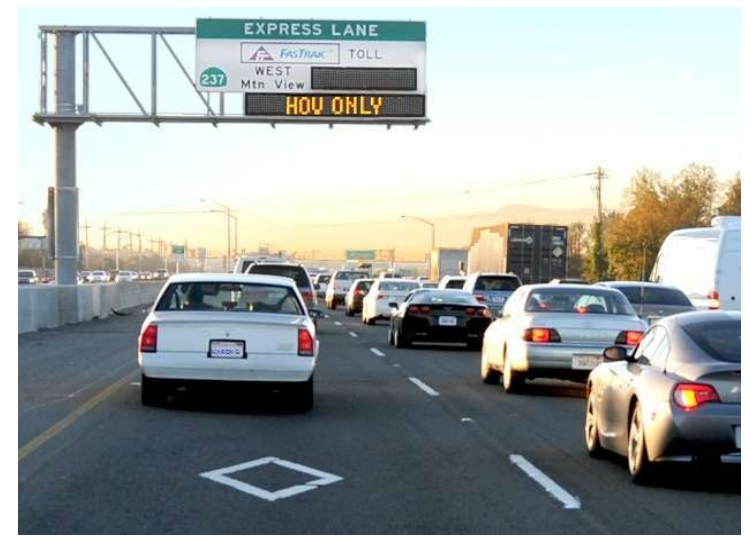

(a)

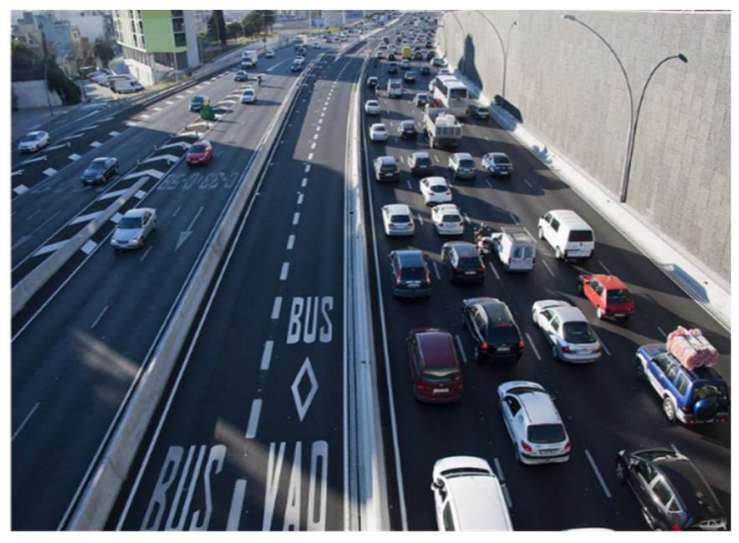

(b)

Figure 2. Dynamic versus static high-occupancy-vehicle (HOV) lanes: (a) adjacent HOV lane (Photo source: Nexobus); (b) segregated HOV lane (Photo source: Santa Clara Valley Transportation Authority, San Jose, CA, USA). 
Additionally, the flexibility to use them in special situations, for instance to respond to the closure of general-purpose lanes because of an accident or road works, is also limited. Finally, possible errors in the conception of the infrastructure (e.g., due to an ill-defined origin-destination demand structure) are irreversible and imply a huge waste of resources.

Congestion reduction should be the fundamental goal when implementing any traffic management strategy. This largely contributes to traffic efficiency, safety, and to the protection of the environment. For example, the potential for a reduction in pollutant emissions and fuel consumption during free-flowing episodes by applying traffic management strategies (e.g., dynamic speed limits) is of the order of 4-6\% (e.g., [34,35]). However, this reduction could be much larger if the dynamic speed limits strategy was able to relieve congestion, as traffic emissions peak in congestion and stop-and-go situations [36]. HOV lanes or dynamic speed limits systems are only examples of traffic management strategies where high investments do not ensure the maximum benefits if not adequately designed. There are other dynamic traffic management strategies experiencing a similar situation. All of them could be improved if some attention was paid to traffic engineering concepts instead of concentrating only on the introduction of the latest technologies. Properly operated, all of them would not only make road traffic safer and more efficient, but they could contribute to a reduction in air pollution and fuel consumption, which are closely linked to congestion. Unfortunately, many viable traffic management strategies and their potential benefits are unknown or unexplored by policy-makers with responsibilities in the field. In such a context, traffic management pedagogy should be a priority. This situation might be due to the fact that the performance of traffic administrations is mainly evaluated according to safety statistics. Note that the safety-related strategies (for example the eCall system) receive much more attention and are generally well-perceived by society because of their direct purpose of saving lives [37].

\subsection{Autonomous Vehicles (AVs)}

The attractiveness of AVs to today's society is unquestionable, like the expectancy of the enormous benefits that they could bring in the future. The whole of society will be affected by their introduction: passengers, pedestrians, bikers, cyclists, workers, etc. [38-40]. They will enhance the mobility of people with special needs [41]. AVs are also said to be the solution to congestion and accidents in the future mobility. Unfortunately, these goals will not be completely achieved if their introduction is not accompanied by management strategies [42,43].

First, note that $\mathrm{AVs}$ are being designed with very conservative driving parameters, aiming at drivers' safety and comfort. For example, AVs are normally instructed to drive with a minimum time gap of $2 \mathrm{~s}$. This gap measures the time between the passages of two consecutive vehicles. Traditionally, the "2-s rule" has been a rule of thumb that has been suggested by many traffic authorities as a car-following policy (i.e., $1 \mathrm{~s}$ to react and $1 \mathrm{~s}$ to apply the brakes in time to avoid an obstacle). In practice, few drivers apply this rule, being the average human time gap approximately $1 \mathrm{~s}$ [44]. If $\mathrm{AVs}$ are introduced with the conservative $2 \mathrm{~s}$ gap, vehicle throughput will be reduced and congestion will increase, especially when their penetration rate becomes high. The time gap is not the only conservative parameter in the design of AVs. Other behavioral parameters, such as acceleration or the aggressiveness in lane-changing and merge assistance, are also very smooth and conservative with respect to the current average driver's behavior. Making AVs more aggressive is not a solution, as several surveys have already stated that this would not be accepted by passengers [45]. Other inefficiencies of AVs include the uncoordinated (i.e., individual) lane and route assignment, which could lead to an extremely uneven distribution of flows on the freeway section or across the road network. Nevertheless, these considerations could be compensated for by the ability of AVs to reduce instabilities in the traffic flow proportionally to their penetration rate. Consequently, congestion, accident rates, and the emission of air pollutants could also decrease [46].

A second problem in the conception and design of AVs relies on the individual and consumer-oriented development. Wardrop's second principle arises again: the best individual performance does not guarantee 
the optimal performance of the system. Ad-hoc traffic management strategies, which for a long time will need to consider a mixed traffic environment with autonomous and traditional vehicles, stand out as essential again. The need for a cooperative management of AVs for the sake of efficiency has already been demonstrated. On freeways, platooning could be a mode of cooperation with high potential, as AVs could drive at high speeds with very small spacings (as if they were a road train) without compromising safety. Similarly to single AVs, platoons require their own management strategies, especially in a mixed-traffic situation $[47,48]$. Some initiatives have already been outlined, but have not been completely defined. For example, when the average speed exceeds $50 \mathrm{~km} / \mathrm{h}$, the capacity is expected to noticeably increase, even if platoons and individual vehicles (either autonomous or traditional) share lanes. With congestion, dedicated lanes for $\mathrm{AV}$ platoons are advisable. One plausible option would be the dynamic assignment of particular lanes to platooning, either exclusively or shared with HOV vehicles or with vehicles with other types of priority. Such strategies must also ensure that platoons do not prevent mandatory lane changing of other vehicles near merges and diverges. In conclusion, it is clear that traffic management strategies in the presence of AVs will be essential to fully achieve the benefits of driving automation. The good news is that the implementation of such strategies will be easier than today, as the behavior and control of AVs will be much more predictable than that of human drivers. The main difficulties will appear in the agreement on the definition of the strategies and the interoperability among different brands, countries, etc.

Furthermore, fully autonomous vehicles (i.e., when the highest automation level is achieved) are expected to increase the mobility rate in terms of vehicle- $\mathrm{km}$ travelled. The reason for this increase is that transportation costs will be lower, linked to savings in labor costs and to a better vehicle amortization. AVs are expected to be expensive during the early years of their implementation, and thus not affordable for the average citizen. Most of them will be introduced as part of the vehicle fleets of freight transport or vehicle sharing companies and will be heavily utilized. This reduction of transportation costs will boost competitiveness, but it could lead to more congestion. One solution would consist in increasing AVs' average occupancy. In this way, the total vehicle fleet could be reduced.

With regard to safety, the best results would be achieved if traffic exclusively consisted of AVs. Prior to the utopian situation, there will be a long period in which AVs will share roads with traditional vehicles. In this context, their different behaviors could be a new source of accidents. Furthermore, some probability of an accident will always exist, even when AVs prevail. In fact, the programming of fully $\mathrm{AVs}^{\prime}$ response to near-accident events is one of the most controversial issues that we face [49-51]. Think, for example, of a child that suddenly crosses a two-lane road to catch his ball in front of an $\mathrm{AV}$ with two adults. If the AV steers to the left, it will enter the opposite lane and if it steers to the right, it could crash into a wall. Should the AV try to save the child's life, compromising those of its passengers? Is the life of a child more valuable than that of one or two adults? Administrations, researchers, and all involved stakeholders attempt to reach a fair agreement on acceptable ethical postulates [52,53]. Another typical example used as a starting point for reflection is the "trolley problem" [54], whose initial goal was to analyze the ethics of abortion. It introduces an event in which an uncontrolled trolley enters a track where five workers are performing their tasks. The trolley driver has the option to drift the trolley towards a sidetrack with only one worker. If he steers, the number of deaths will decrease, but it will be himself instead of fate who has the responsibility of one person's death (Figure 3).

Two main ethical disciplines are being used to solve this and other similar ethical problems: consequentialism (especially utilitarianism) and deontology. In the first vision, actions are not judged by their nature (e.g., if death is undesirable in any case) or by the goal of the agents (e.g., if there is intention or not to kill), but rather by the "goodness" or "utility" (broadly speaking) associated with their consequences $[51,55,56]$. In a deontological or Kantian framework, the moral rightness of an action depends on the intention with which it was done, regardless of its consequences [55]. At present, only Germany has released 20 general ethical guidelines in this regard, that at least serve as a launching pad for further analyses [53]. Many other aspects, such as the impact on the territory, economy, and labor market, need to be considered to achieve a successful implementation of AVs [57-59]. 


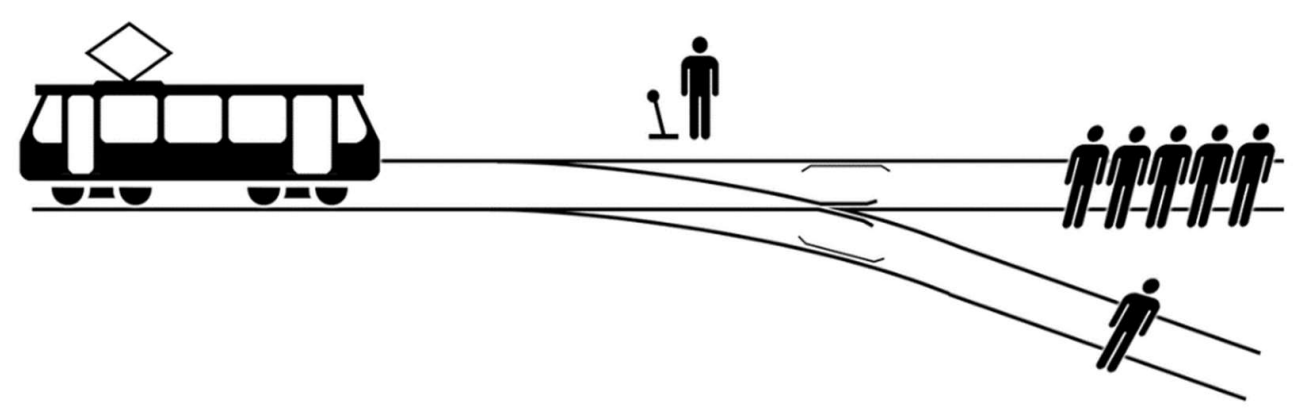

Figure 3. The trolley problem [54]. (Figure of McGeddon. Available in (https:/ /en.wikipedia.org/ wiki/File:Trolley_problem.png under the CC BY-SA 4.0 license).

Many decisions regarding AVs' usage policies will have to be made: will a driving license be necessary? What will the mandatory technical inspections be like? What about the role of insurance companies? Which protocols must be established to protect data against cyber-attacks and to ensure privacy? Among these, the policies related to liability in the event of an accident are the most challenging. Carmakers claim that they cannot hold full liability. What about software developers? Or technicians who mounted any particular component? Or even the owner that did not fulfil the mandatory software updates? In fact, the solution of these arguments will probably set the pace for fully AVs to penetrate the market. Disregarding populist announcements and the desire for technological consumption, further research is needed on these topics, and we should not expect the widespread adoption of fully AVs in the short term [60].

\subsection{E-Vehicles}

Pollution and air quality are an increasing concern in metropolitan areas. Road transport is a major contributor to air pollution, and, for example, in Europe it accounts for nearly $20 \%$ of all greenhouse gas emissions. The European Union (E.U.) and the governments of its member states are committed to finding a solution, and important regulations have already been introduced. Municipalities increasingly ban private vehicles from accessing urban centers, or charge them to access these centers, putting special pressure on diesel engines, whose use could be heavily restricted soon. Similar situations and restrictions exist in other continents. Although the widespread use of electric vehicles (EVs) would help to reduce pollutant emissions and noise, consumers are reluctant with respect to their power and autonomy. Electrical motors are extremely efficient, but infrastructural needs (mainly charging points) as well as battery capacity and the subsequent autonomy range anxiety [61] are still factors that limit the public uptake of EVs [62]. Norway, with about 500,000 EVs at the start of 2017 (more than in the USA), is the leader in Europe. China leads the world market with about 600,000 EVs on its roads and 5 million planned for 2020 [63]. Initially, traditional carmakers did not seem very enthusiastic about EVs, and focused much more on automation, fostered by consumer's desires. In this context, consortiums of technological industries and start-ups take the lead in the manufacturing of EVs. Currently, their efforts to develop EVs are paying off, and many governments offer tax reductions, exemptions in parking fees and tolls, and bonus payments or premiums to foster their adoption $[64,65]$. For example, Norway offers an exemption of $25 \%$ VAT on purchase, a $40 \%$ reduced company car tax, no purchase/import taxes, no annual road tax, no charges on toll roads, a $50 \%$ price reduction on ferries, free municipal parking, access to bus lanes in Oslo (only for carpooling +2 during rush hours), and the possibility of recharging for free at public charging stations. These kinds of measures imply a slight change of trend in the E.U. [66].

Lower prices, the possibility of making longer journeys without recharging, and the widespread availability of fast charging stations are the crucial challenges for the popularization of EVs [67], but not the only ones. Users also penalize their fast obsolescence, the few specialized car mechanical workshops available for their maintenance and repairs, their high insurance costs, and their limited ability to travel 
with trailers. From the safety point of view, high voltage batteries are thought to be dangerous as they can burst into flames in the event of an accident. However, this is not much different than carrying a large tank of a highly flammable liquid in traditional cars. EVs also need to consider sustainability. For example, large amounts of rare metals are necessary to assemble the batteries. Lithium-ion batteries are being used in significant quantities for automotive propulsion [68], and cobalt and graphite are increasingly in demand too. This means that large-scale recycling schemes are necessary to avoid the depletion of natural resources and to prevent the emergence of uncontrolled landfills. In addition, because these metals are usually obtained from developing countries, governments should be attentive to the establishment of policies for their protection. Another issue would be how to obtain the electrical energy that is required to power a large EV fleet, which would require the upgrade of the whole electrical power system. This is why there is a current of thought defending that, for those who really want to preserve the environment, the best option is not to buy an electrical car, but to use public transportation or share vehicles instead.

An intermediate alternative between traditional and electric vehicles are hybrid and plug-in hybrid vehicles. Longer trips without recharging are possible, but emissions are not eliminated and fuel dependence continues $[69,70]$. In addition, other inconveniences are still present (e.g., price, insurance, reparations, double technology). These vehicles are only a temporal solution.

\subsection{Sharing Systems}

In Los Angeles (USA), the most congested city in 2017, 77\% of the population own their cars [6]. In the U.K., the average car is only in motion during $4 \%$ of its life [71]. Many city centers (e.g., London, Oslo, and Paris) already ban or charge for the access of private cars. In this context, the shift from vehicle ownership to vehicle use has started [72]. In fact, it also represents a change towards a more engaged society with a smaller vehicle fleet. Car, bike, or motorbike sharing systems have turned out to be a trendy complement to collective transportation, looking for an efficient, economical, and environmentally friendly urban mobility. All of them consist of a pay-per-use vehicle fleet that can be driven within a service area.

Originally, vehicle sharing systems were organized as two-way, in which users had to take the vehicles back to their original pick-up stations. Two-way systems were received by consumers as flexible rent-a-car initiatives, but they did not suppose a new paradigm in urban mobility. This required one-way systems, in which the vehicle can be picked-up and returned anywhere within a service region. One-way systems can be station-based, i.e., vehicles must be picked up and left at specific stations or "depots", or free-floating, in which vehicles can be found and dropped off at any parking spot inside the service area. There are pros and cons to both approaches $[73,74]$. For instance, car-sharing vehicles are usually electric, and their concentration at depots allows for installing more efficient charging points. In contrast, the accessibility of the system will be determined by the number, position, and size of the stations, which must be carefully planned to cover all subareas of the service region, and to make the probability of empty and full stations low. Request and return demands at each subarea must be considered to keep repositioning operations (i.e., artificially recovering the system from demand unbalances) to a minimum, and, thus, making the system economically viable. Another problem of station-based systems is the space requirement for the stations, as space is especially scarce in city centers. Several car-sharing companies adopted free-floating systems to avoid these inconveniences. Nevertheless, free-floating systems need to be operated based on reservations, which implies an increase of the average service time of each vehicle, and, thus, a reduction in their availability for a given fleet size. Another problem of free-floating systems is that their accessibility randomly varies in space and time (i.e., lower at peak periods due to less free vehicles). This may penalize the users' confidence in the system.

Other vehicle sharing initiatives include ride-hailing and peer-to-peer (P2P) sharing. Ride-hailing allows the owners of private vehicles to connect through an app or website with other people that 
want to share the total or part of their trips. In P2P, owners offer their vehicles through similar media for a particular area and a period of time, when they do not need them.

In summary, it can be said that the potential of well-managed sharing systems and the benefits they can bring to society are indisputable. However, some risks are envisaged in their implementation. For example, vehicle sharing systems tend to be promoted by automotive companies or start-ups, without a clear determination for the social optimum in mobility terms. This results in partial spatial coverage, the coexistence of several non-interoperable systems, "trial and error" pilot tests, etc. Policy-makers should encourage city-wide systems, based on an in-depth analysis of the global users' needs and boundary conditions of the service area [75]. In addition, two facts could impede the desired reduction of the vehicle fleet by the introduction of car-sharing initiatives. Firstly, most sharing companies use small vehicles and customers often use them alone. This means that the average vehicle occupancy tends to be low. Secondly, a recent study that analyzed the results of a very comprehensive survey on ride-hailing use, performed in several North American cities, concluded that almost $50 \%$ of ride-hailing trips would have been made by walking, biking, mass transit, or avoided. In other words, in their current design, these systems encourage vehicle usage and could contribute to congestion and pollution [76].

Overlooking these benefits and penalties of car-sharing, it can be observed that their usage is still restricted to a small niche of society. This is not due to the price of using the system. Reducing the already reasonable price of sharing and hailing systems would only led to the demise of many companies due to subsequent economic losses. There are other reasons that explain why people do not shift to these services: (i) a lack of service outside of metropolitan areas, (ii) human reluctance to change, (iii) a lack of technological skills (e.g., to make a reservation and pay), (iv) a loss of privacy and comfort (e.g., to carry individual items), (v) displeasure with vehicle cleanliness, and (vi) an inclination to consumption and ownership [77-80]. Regarding this last reason, the re-conceptualization of travelling as a "consumption of distance" could help to change the current mindset [81]. With regard to interurban trips, the combination of sharing and mass transit is expected to make them more popular in a near future. In fact, this need is already being considered by the developers of the so-called Mobility as a Service (MaaS) on-demand mobility solutions. This is a new comprehensive transport concept that is similar to global offers in the telecommunications sector. In these solutions, "mobility operators" will have access to the timetables, real-time location, fares, etc. of the existing transport service providers. Users, usually through a mobile phone app, will provide their origin and destination points, and will be given a seamless combination of different modes of transport, including intermodal collective transport, taxis, shared vehicles, and bicycles. Users will only deal with the global mobility operator and pay a flat rate, per trip, per period, per distance ... depending on their needs. It is clear that MaaS and vehicle sharing will exhibit strong synergies. MaaS is already technologically feasible; however, there is a long way to go before reaching agreement and coordination among all of the parties involved, as well as the establishment of the corresponding policies [82-85]. Informative and educational campaigns could help to confront the remaining reasons behind people's disinclination to consume vehicle sharing systems. Also, some administrations are considering to provide incentives to users, at least at the early stages of these systems. For example, shared vehicles could have granted access to exclusive areas and restricted lanes, or economic subsidies could be provided to compensate for the disutility of waiting, accessing the system, or sharing the vehicle with other passengers [86]. Nevertheless, the role of governments and administrations in the regulation of potentially environmentally friendly practices, such as vehicle sharing or MaaS, is generally affected by an intricate chain of interests, as there are many stakeholders affected. Both an adequate planning of these systems and an agreement between all the parties involved in the sharing economy are essential to advance towards a more sustainable mobility [87].

\section{Technology in Future Personal Mobility: Will Scotty Beam Us Up}

Perhaps the day will come in which we can ask for teleportation, like Capitan Kirk did [88]. This idea seems distant and against the laws of physics, but other film-inspired modes of transport are 
already being developed or even operated on small test sites. Monorails, magnetic levitation (maglev) trains, and personal rapid transit systems or drones (to transport goods) are only some examples. The following sections focus on transportation systems that do not operate yet but have been announced by their promoters as the solution to current mobility problems. Transportation solutions that are faced in the previous sections illustrate cases where technology is being applied with more or less acceptance and success, but with the potential to become real innovations in personal mobility. On the contrary, consumerism and/or overconsumption as well as technology attractiveness seem to be the incentives for the proposal of the following modes, according to their inherent disadvantages to become a reality.

\subsection{Flying Cars}

Several enterprises work on flying cars, whose aesthetic recalls Spinners [89]. Indeed, current prototypes include vertical take-off and landing (VTOL) aircrafts or drones made of lightweight but resistant materials and with improved power density engines. The first commercially available flying car, the Dutch Pal-V Liberty, can already be reserved (Figure 4). It was presented at the Geneva Motor Show 2018. According to its developers, it takes 5-10 $\mathrm{min}$ to change from a three-wheeled car to a gyroplane and reaches $160 \mathrm{~km} / \mathrm{h}$ on the road and $180 \mathrm{~km} / \mathrm{h}$ in the air, at a maximum height of $3500 \mathrm{~m}$. For its part, Uber plans to launch an aerial taxi service in 23 cities across 13 countries by 2020. Other firms, such as Google (with the start-up Zee.Aero) or Airbus (Vahana), are behind similar projects. Flying cars attract governments as well as traditional car manufacturers. Dubai plans to introduce a flying taxi at the World Fair in 2020, whereas Toyota supports a group of Japanese inventors to launch a flying car (SkyDrive) by the 2020 Summer Olympics in Tokyo.

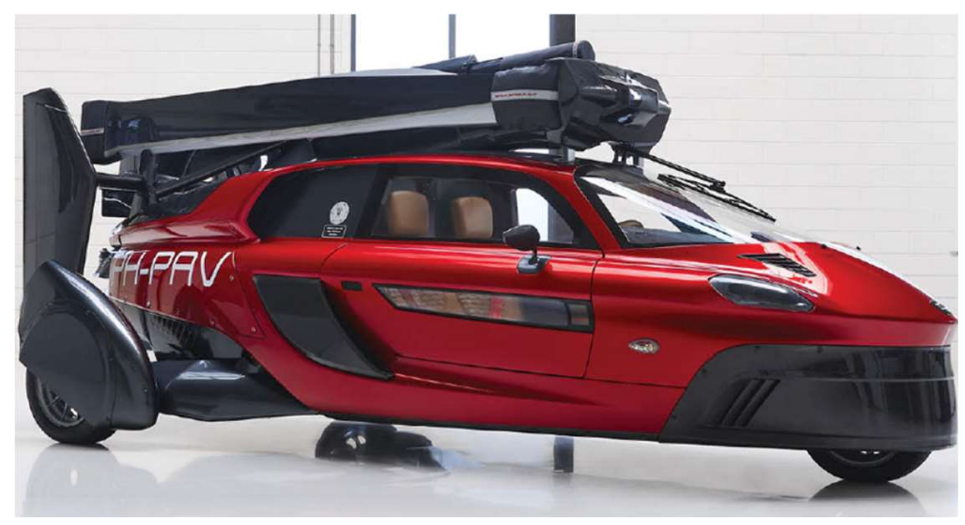

Figure 4. The Dutch Pal-V Liberty flying car [90].

In spite of the technological advances in the air industry, the generalized adoption of airborne vehicles seems unfeasible if important concerns are not tackled. Technically, they are too sensitive to weather and load weight restrictions, which would limit their usage. Ignoring these factors could lead to severe safety problems. Battery improvements are also crucial, because most of them are "clean" (i.e., electrical) [91]. Socially, their high price (and surely that of the related insurances) and increased noise levels would soon outsprint their initial appeal. Moreover, drivers should have a sort of pilot license, which would be difficult and expensive to obtain. The required physical conditions and the complicated topics to cover (aerodynamics, mathematics, instrumentation, navigation techniques, etc.) could also limit the spectrum of users. Changes in regulations affecting other means of transport (e.g., aviation) would be necessary, as well as the adaptation or construction of new infrastructures for take-off and landing operations. It seems inadvisable to use airports or streets for these purposes to prevent operational and safety problems. The need for such special sites would reduce the flexibility of possible itineraries. This leeway would even be lower in the case of long journeys, since it would be necessary to plan where to recharge or refuel. Less severe issues, such as the risk of falling garbage, would also appear. 


\subsection{Hyperloops}

Another transport mode predicted by science-fiction was the "pipeline travel". Currently known as the hyperloop, it appeared for the first time in the animated film The Jetsons [92]. The most famous real hyperloop initiative was launched in 2013 by the well-known entrepreneur Elon Musk. He described a means of transport based on magnetic levitation, where capsules act as wagons and travel inside a low-pressure tube at very high speeds (ideally $1200 \mathrm{~km} / \mathrm{h}$ ), supported by a bed of air [93]. A 2-year Hyperloop Pod Competition was launched, and the best designs presented were supported in the building of small prototypes and their testing on a $1.25 \mathrm{~km}$ track. In the second event of the competition, held in August 2017, the WARR hyperloop of the students of the Munich Technical University was the fastest, reaching a top speed of $324 \mathrm{~km} / \mathrm{h}$. In fact, it surpassed the commercial Virgin Hyperloop One, whose top speed in its last test carried out in Nevada was $309 \mathrm{~km} / \mathrm{h}$ [94]. Nevertheless, Virgin states that the final version of their Hyperloop One, which is being developed partly in Spain, will be able to travel at $1080 \mathrm{~km} / \mathrm{h}$. They plan to launch it in Abu Dhabi in 2020, as long as the corresponding legislation is ready by this date. Several other companies work on their own hyperloops, including the Boring Company of Elon Musk. In fact, the company has already been given permission to begin digging a transportation tunnel in Washington D.C. The goal is to enable a 29-min journey between the capital and New York City.

In this context, the idea of the so-called Urban Hyperloops is also gaining momentum. According to their promoters, these are associated with a more sustainable urban mobility concept, which would use smaller-scale hyperloops with many small stations (of the size of one parking space) and vehicles to move, preferably, pedestrians and cyclists across big cities. This would encourage private owners to leave their vehicles at home. Although technologically updated, there is not any new urban transportation paradigm in the Urban Hyperloop concept, but a promise of a faster and accessible on-demand transportation system. The question is: how this is going to be achieved? How will the hyperloop technology handle multiple routing and network congestion? Still, there is no clear answer to these questions.

Although hyperloops are very attractive, and in spite of the tests that are being conducted, there are many doubts about whether they can become a universal mobility solution. Technical questions persist. For example, the expected speeds have not been reached yet. Furthermore, long hyperloops would need to pump millions of cubic meters of air to create the vacuum in the tube. Constructing such near-vacuum tubes would be a challenge in itself, and even more difficult to attain with the thin walls of current designs. The air pressure outside would apply an enormous force against the tube. In this context, the vibrations caused by the high-speed pods or expansion and contraction movements due to changes in temperature could have disastrous repercussions. In this regard, several scientists claim that safety problems could be very serious [95-97]. As an example, it is asserted that any small rupture or crack in a capsule would expose passengers to a hard vacuum, causing them to die as if they were in space. Others contend that a breach in the tube could kill everybody, because air would rush into the tube at about the speed of sound. Fatal predictions about the consequences of an individual pod crashing exist too: it would generate a cascading failure causing a pressure wave to shoot down the tube at the speed of sound, destroying all other capsules. The former examples help us to imagine to what extent hyperloops would be vulnerable to terrorism.

Even supposing that the required technology is available, an economic feasibility assessment should be carried out before devoting large amounts of money, time, and energy to the concept. The necessary initial investment would be a big problem. Tubes are conceived to be mainly underground. The hyperloop infrastructure was promised to be much cheaper than that of other transportation alternatives on the basis of the progressive reduction of the cost of tunneling, which is uncertain. In addition, other important costs, such as those related to the acquisition of land or to the installation of safety measures, have been underestimated. The first analyses estimate that $€ 49$ million will be needed to build $1.6 \mathrm{~km}$ of hyperloop [98]. Finding areas where cheap tunneling is possible and does not damage other infrastructures, dwellings, or even natural environments would also limit the 
connection of dense urban areas to the system. Most experts agree that the construction of smaller and simpler hyperloops for freight (especially light, time-sensitive goods) is a much more feasible option.

\subsection{Teleportation}

Also known as teletransportation, the concept of teleportation would consist in instantaneously converting matter into minute particles, energy, or data at one location and recreating it in its original form at another. Although the concept was popularized by the science fiction television series Star Trek [88], the idea rose up much earlier. The first recorded story on the topic was based on The Man without a Body [99], where a machine called a Telepomp was able to transform matter into energy and transmit it to a receiver.

There is great controversy about whether the teleportation of people and goods could ever come true. That would really be a breakthrough, as most of the problems faced in the former sections (congestion, pollution, safety, the need for large infrastructures, etc.) would disappear, or, at least, mutate into completely different problems. Advances at the microscopic level have already been achieved. The latest and most significant was attained by Chinese researchers, who teleported a photon from the Jiuquan Satellite Launch Center (Dunhuang, Jiuquan, Gansú, China) to a satellite in orbit more than $500 \mathrm{~km}$ away [100]. The basis of this so-called quantum teleportation is the phenomenon known as quantum entanglement. In simple words, when two subatomic particles are created at the same place and time, a special link is created between them. When the state of one of the particles changes, the other changes as well, even if they are separated by large distances. If, for example, the first entangled particle interlays with a third one and it undergoes a state change, this is replicated in its twin. That is, the twin embraces the existence of the outsider, which is said to have been teleported. The quantum state information of this third particle has been transmitted. Thousands of commentators, businessmen, and the general public are excited about the idea of instantaneous trips. However, the teleportation of human beings or simply of large quantities of inert matter is unlikely to become a reality. Firstly, (quantum) teleportation can only transfer information about an object, but not the object itself. So, only a copy would be transmitted. Secondly, transmission of billions of particles would require an enormous bandwidth and an extraordinary amount of power, which seems physically impossible.

Ethical issues also arise. Even if large quantities of matter could be teleported in the future, would a teleported person be the same individual? What happens to the original person? Would his/her personality, way of thinking, or memories remain? These topics could be as challenging as those mentioned above.

\section{Multicriteria Analysis of Different Innovative Transportation Modes and Strategies}

In order to assess what has been discussed in the previous sections, a multicriteria analysis has been performed under a hybrid approach that combines the Analytic Hierarchy Process (AHP) and evidential reasoning (ER), as described in Section 2. This allows us to consider all of the innovative transportation alternatives addressed in this paper, comparing current transport modes/strategies (with the quantitative empirical data available) with futuristic solutions, which have not been implemented yet. In this last case, many uncertainties exist, and only qualitative, and, to some extent, subjective criteria can be applied. A belief decision matrix, resulting from the joint consideration of the sources of information detailed in Section 2, has been constructed (see Table 1). The primary goal of this matrix is not to choose a single alternative, but to make readers aware of their strengths and weaknesses from a multi-dimensional point of view.

The transportation modes/management strategies to compare are placed in columns, while their impact according to different criteria appears in rows. Trying to cover the most important standpoints from a sustainable mobility perspective, the following criteria (with their respective weights, $\alpha_{j}$ ) are addressed:

- Mobility: to what extent the alternative assessed helps to improve the efficiency of mobility, whether by directly or indirectly relieving current congestion or by offering a new optimal mobility solution. Weight of the criteria: $\alpha_{m}=1$. 
- Safety and security: to what extent the alternative assessed directly or indirectly contributes to diminishing the number of accidents. Also, how secure is the alternative against new forms of terrorism (e.g., cyberattacks). $\alpha_{s s}=1$.

- Environment: to what extent the alternative assessed is environmentally friendly. This includes topics such as the quantity of harmful emissions, noise, and land occupation. $\alpha_{e}=1$.

- Social scope: to what extent the alternative assessed is equitable and inclusive. Assessment of the barriers imposed to the inclusion of sectors of population depending on factors such as age, health, and income. $\alpha_{s o}=1$.

- Spatial scope: applicability of the assessed alternative to a wide variety of spatial contexts. For example, if it is restricted to urban centers or not. $\alpha_{\text {spa }}=1$.

- State-of-the-practice: to what extent the addressed alternative could be immediately applied or how difficult the accomplishment of the necessary developments/improvements are expected to be. $\alpha_{s p}=0.85$, as technological advances may change the state-of-the-practice of some alternatives soon.

- Economic feasibility: addresses the sustainability of the system in economic terms, from the point of view of the administrations or operating companies. The users' affordability is not addressed here, as it is included in the "Social scope" criterion. $\alpha_{e c}=0.75$, taking into account that innovations are usually expensive at their first stages but become affordable with time.

- Privacy issues: to what extent the alternative encroaches on people's privacy. For example, the use of aggregated data is considered less detrimental than that of individual data. $\alpha_{p i}=0.5$. Although privacy must be guaranteed as much as possible, ensuring an optimal future mobility can be a priority. Possibly, privacy could be penalized to a certain extent, always after explicit user acceptance and under the supervision of a responsible entity.

Table 1. The multicriteria analysis of different innovative transportation modes/strategies.

\begin{tabular}{ccccccccc}
\hline IMPACT & $\boldsymbol{\alpha}_{\boldsymbol{j}}$ & ATMS & CCAV & EV & SHS & FC & HYP & TP \\
\hline Mobility & 1 & 5 & 5 & 3 & 4 & 3 & 3 & 5 \\
Safety and security & 1 & 5 & 4 & 3 & 3 & 2 & 2 & $?$ \\
Environment & 1 & 4 & 4 & 5 & 4 & 2 & 2 & 5 \\
Social scope & 1 & 3 & 5 & 3 & 4 & 2 & 2 & $?$ \\
Spatial scope & 1 & 3 & 4 & 3 & 4 & 2 & 1 & 5 \\
State-of-the-practice & 0.85 & 5 & 4 & 5 & 5 & 3 & 1 & $?$ \\
Economic feasibility & 0.75 & 5 & 4 & 5 & 5 & 1 & 2 & $?$ \\
Privacy issues & 0.5 & 3 & 2 & 3 & 2 & 3 & 3 & $?$ \\
\hline TOTAL GRADE & & $83.1 \%$ & $82.8 \%$ & $74.6 \%$ & $78.9 \%$ & $44.5 \%$ & $39.0 \%$ & $?$ \\
\hline Social acceptance & & $57.1 \%$ & $92.9 \%$ & $66.7 \%$ & $58.8 \%$ & $66.7 \%$ & $75.0 \%$ & $100.0 \%$ \\
\hline
\end{tabular}

Note: (1) a question mark is used when uncertainty cannot even be dealt with with a well-posed subjective analysis. (2) $\alpha_{j}$ stands for the relative weight of the criteria; ATMS stands for "active traffic management strategies"; CCAV for "connected and cooperative autonomous vehicles"; EV for "electric vehicles"; SHS for "sharing systems"; FC for "flying cars"; HYP for "hyperloops"; and TP for "teleportation".

In the multicriteria analysis, each impact has been evaluated according to five possible grades, which have been converted into scores (in brackets): very positive (5), positive (4), insignificant (3), detrimental (2), and very detrimental (1). The given scores result from the expert consideration of all sources of information, namely: indexed papers, non-indexed papers, conferences, interviews, in-situ visits, author's knowledge, etc. Objective and quantitative information coming from relevant scientific publications has always prevailed when available. However, scientific publications are scarce for the case of the futuristic proposals addressed. The final result for each alternative is expressed as a percentage of the maximum possible grade.

According to the multicriteria analysis presented in Table 1, the widespread use and implementation of active traffic management strategies would be the most beneficial strategy considering a wide range of impacts and at the present time. Next, an optimal introduction of connected and cooperative autonomous 
vehicles (CCAVs) and the generalization of sharing systems stand out as highly desirable as well. Of course, these results should be taken with caution, as they include some qualitative and provisional considerations, and they do not account for possible synergies between different developments. For instance, sharing systems whose fleets could be composed of electric high occupancy autonomous vehicles would be significantly more beneficial. In addition, some of the aspects considered will change with time. For example, both the state-of-the-technology and the price of AVs are expected to become more favorable in the coming years, which would result in different grades for most of the impacts considered. Although high volatility has been included in the analysis by means of lower weights, some uncertainty still exists. Therefore, these limitations and others discussed in the paper, especially regarding future transportation modes, advise against taking the numeric results of the former multicriteria analysis as a ground truth. In fact, numerical results are not the goal of any assessment applying evidential reasoning. This does not detract from the performed assessment value. On the contrary, it supports the central idea of this paper.

Additionally, one final row has been added in Table 1 to rate the social acceptance of the mode/strategy under consideration. Social acceptance is defined as the willingness of the different stakeholders (i.e., users, administrations, private companies ... ) in the deployment and application of the considered technologies and strategies. In order to assess this factor, the inputs provided by all of the sources of information used (see Section 2) have been classified into two groups considering whether their position mostly highlights the benefits (i.e., positive acceptance) or the penalties and problems (i.e., negative acceptance) of the alternative considered. Table 2 provides partial evidence of the assessment of social acceptance, considering only the published sources of information that show a clear attitude towards these modes/strategies, either verbatim or inferred from their content. Note that the classification of these references as being "for" and "against" one particular mode/strategy exclusively takes into account the current state-of-the-art of these alternatives. Therefore, there exist references that, for example, have been classified as being "against" CCAV because they focus on their undesirable current issues, although stating that, in the long term, they could result in being beneficial as long as these problems are properly addressed. The level of social acceptance under these terms is expressed as a percentage, which represents the fraction of positive acceptance positions with respect to all of the sources of information that have been considered for this purpose. The inclusion of social acceptance aims to illustrate that the social benefits of the implementation of a given technology are generally not related to its social attraction and interest.

Table 2. The literature review regarding the social acceptance of different innovative transportation modes/strategies.

\begin{tabular}{|c|c|c|c|}
\hline Mode/Strategy & Acceptance & References & Social Acceptance \\
\hline ATMS & $\begin{array}{l}\text { Positive } \\
\text { Negative }\end{array}$ & $\begin{array}{c}{[5,16,31,97]} \\
{[18,19,27]}\end{array}$ & $57.1 \%$ \\
\hline CCAV & $\begin{array}{l}\text { Positive } \\
\text { Negative }\end{array}$ & $\begin{array}{c}{[16,37-41,43,45,46,57,60,97,98]} \\
{[49]}\end{array}$ & $92.9 \%$ \\
\hline EV & $\begin{array}{l}\text { Positive } \\
\text { Negative }\end{array}$ & $\begin{array}{c}{[5,41,57,63,65-67,70,77,78,97,98]} \\
{[61,62,64,68,69,101]}\end{array}$ & $66.7 \%$ \\
\hline SHS & $\begin{array}{l}\text { Positive } \\
\text { Negative }\end{array}$ & $\begin{array}{c}{[5,41,57,72-74,77,84,97,98]} \\
{[19,78,79,83,85-87]}\end{array}$ & $58.8 \%$ \\
\hline FC & $\begin{array}{l}\text { Positive } \\
\text { Negative }\end{array}$ & $\begin{array}{c}{[90,91,102]} \\
{[97]}\end{array}$ & $75.0 \%$ \\
\hline HYP & $\begin{array}{l}\text { Positive } \\
\text { Negative }\end{array}$ & $\begin{array}{c}{[93,94,97,98,103-105]} \\
{[95,96]}\end{array}$ & $77.8 \%$ \\
\hline TP & $\begin{array}{l}\text { Positive } \\
\text { Negative }\end{array}$ & {$[100,106-109]$} & $100.00 \%$ \\
\hline
\end{tabular}

Note: ATMS stands for "active traffic management strategies"; CCAV for "connected and cooperative autonomous vehicles"; EV for "electric vehicles"; SHS for "sharing systems"; FC for "flying cars"; HYP for "hyperloops"; and TP for "teleportation". 
When comparing the total grade of each alternative with its social acceptance, it can be observed that those modes/strategies that result in more benefits for society are not always those that are more appealing. The case of ATMS is paradigmatic. Dynamic traffic management strategies are theoretically developed and the necessary technology is available. However, non-experts do not appreciate them, probably because they do not understand their objectives and potential benefits. On the contrary, inadequate solutions (at least in their current design), such as hyperloops, are appealing to the population. This situation could be compensated for by the development of information and educational campaigns, as societal acceptance should be related to the expected benefits, and not to the technological attractiveness. Society should become involved to some extent in the development of new transportation alternatives. Only in this way they will become aware of the best solutions for their personal mobility and positively "influence" administrations to make the best decisions.

\section{Conclusions}

This paper warns against neglecting fundamental knowledge and engineering principles in the consumption and implementation of new technologies. It is based on the conviction that technology should not be considered a final objective in itself, but a tool to improve different aspects of society. Using personal mobility as a unifying thread, the paper alerts professionals and administrations of the dangers of ignoring social needs, theoretical foundations, engineering principles, previous experiences, and comprehensive analyses when implementing new technologies. Several specific examples of current malpractice in this regard, as well as possible solutions, are presented.

For example, new technologies and huge computation capabilities provide more traffic information than ever before. However, congestion is still increasing day after day. Each driver attempts to use this information to his/her own benefit, without any centralized control entity aiming at optimizing the entire system. Traffic management centers should use these new real-time data to dynamically enforce drivers to take some actions for the benefit of the whole system. Educational campaigns would help users to better accept this collective way of driving.

In addition, traffic information needs to be accurate, as personal mobility is increasingly dependent on it. The paper presents some paradigmatic cases where the common treatment of traffic data leads to inaccuracies in the traffic state estimation, which are transferred to subsequent traffic studies or information that is disseminated to drivers, which becomes biased or directly erroneous. Simple modifications would suffice to improve these estimations.

The paper also revisits the future of driving automation. Automated vehicles (AVs) are considered to be the solution to all current problems of road traffic: accidents, discomfort, congestion, and pollution. However, this will not be the case if additional changes are not implemented. In this regard, cooperative driving systems are essential. For example, platooning could significantly help to relieve congestion on metropolitan freeways. Ethical issues and a population's reluctance to change will represent other difficulties to solve.

Incontestably, future personal mobility must be environmentally friendly. EVs are the way to go, but there is still a lack of affordable technologies that equal the performance offered by traditional fuel engines. Even in that case, the source of all the electrical power that will be needed remains an issue. Probably, the vehicle fleet should be limited in any case. An efficient public transport system will be essential, and vehicle sharing systems are expected to play an important role in the future. Nevertheless, there is some evidence that users are reluctant to travel with strangers, except when they feel anonymous, as occurs in mass transportation. Educational campaigns that promote the use of vehicle sharing systems are indispensable. Both collective transportation and sharing systems are called to join efforts to offer comprehensive, on-demand mobility services, such as MaaS.

Ongoing projects on futuristic transportation with a high technological component have also been assessed in the paper. In particular, considerations about the advantages and disadvantages of flying cars, hyperloops, and teleportation have been outlined. They could suppose a revolution in personal mobility and could eradicate present troubles, although creating new unthinkable problems. Flying 
cars and hyperloops could be technically feasible, but their current designs involve more handicaps than solutions. Today, their commercialization can only be explained by the desire for technology consumption. For their part, the advances achieved in quantum teleportation cannot be extrapolated to people or freight.

Other factors not directly addressed in this paper should also be considered when exploring the pros and cons of new transportation modes. For example, the world's population is ageing rapidly. Urban development strategies as well as mobility solutions must give due importance to this fact, not being predominantly drafted on the paradigm of technological progress [110]. Also, promising studies suggest that policies aimed at reducing wealth concentration could also be beneficial, because environmentally unfriendly practices related not only to transportation but also to manufacturing, etc., would be distributed too [111].

A final conclusion can be drawn from the paper: personal mobility and technology will continue to be closely related in the future. At present, the prevailing culture of consumption and the lack of research prevents society from making the most of technological development. To some extent, this is due to the fact that technology consumption and ownership are linked to a high status and/or to power and modernity. There is a need for information and education campaigns targeting users, but also administrations, so that they think and act from a more social point of view. The global improvement of personal mobility (i.e., the social benefits) should hold the reins, adapting technology to its needs. Only in this fashion will the future of transport systems be more sustainable, inclusive, and efficient. This argument could also be applied to any other discipline or field, apart from transportation and mobility. The random consumption of technology is omnipresent, while technology must respond to the demands of society and not create them.

Author Contributions: Investigation and resources, M.M.-D. and F.S.; writing (original draft preparation), M.M.-D.; writing (review and editing), F.S. and I.P.

Funding: This research was partially funded by the Spanish Ministry of Economy and Competitiveness (Ministerio de Economía y Competitividad, Gobierno de España), grant number TRA2016-79019-R/COOP. The APC was funded by Spanish Ministry of Economy and Competitiveness (Ministerio de Economía y Competitividad, Gobierno de España).

Acknowledgments: The comments provided by anonymous reviewers, which have helped to improve the paper, are gratefully acknowledged.

Conflicts of Interest: The authors declare no conflict of interest. The funders had no role in the design of the study; in the collection, analyses, or interpretation of data; in the writing of the manuscript, or in the decision to publish the results. The contents of this paper reflect the views of the authors, who are responsible for the facts and accuracy of the data presented herein.

\section{References}

1. NASA. Mars Climate Orbiter Mishap Investigation Board. Phase I Report. 1999. Available online: ftp:/ /ftp.hq.nasa.gov/pub/pao/reports/1999/MCO_report.pdf (accessed on 15 March 2018).

2. Carbonell, J.; Sánchez-Esguevillas, A.; Carro, B. The role of metaphors in the development of technologies. The case of the artificial intelligence. Futures 2016, 84, 145-153. [CrossRef]

3. Bina, O.; Mateus, S.; Pereira, L.; Caffa, A. The future imagined: Exploring fiction as a means of reflecting on today's Grand Societal Challenges and tomorrow's options. Futures 2017, 86, 166-184. [CrossRef]

4. Bauman, Z. Consuming life. J. Consumer Cult. 2001, 1, 9-29. [CrossRef]

5. van Audenhove, F.-J.; Korniichuk, O.; Dauby, L.; Pourbaix, J. The Future of Urban Mobility 2.0; International Association of Public Transport (UITP) Press: Brussels, Belgium, 2014.

6. Inrix. Inrix Global Traffic Scorecard of 2017. 2018. Available online: http://inrix.com/scorecard/ (accessed on 28 April 2018).

7. Van Wee, B.; Banister, D. How to Write a Literature Review Paper? Transp. Rev. 2016, 36, 278-288. [CrossRef]

8. Saaty, T.L. A scaling method for priorities in a hierarchical structure. J. Math. Psychol. 1977, 15, 234-281. [CrossRef]

9. Saaty, T.L. The Analytic Hierarchy Process; McGraw-Hill: New York, NY, USA, 1980; ISBN 10-0070543712. 
10. Chen, Z.; Chen, T.; Qu, Z.; Yang, Z.; Ji, X.; Zhou, Y.; Zhang, H. Use of evidential reasoning and AHP to assess regional industrial safety. PLoS ONE 2018, 13, e0197125. [CrossRef] [PubMed]

11. Dempster, A.P. Upper and lower probabilities induced by a multivalued mapping. Ann. Math. Stat. 1967, 38, 325-339. [CrossRef]

12. Shafer, G. A Mathematical Theory of Evidence; Princeton University Press: Princeton, NJ, USA, 1976; ISBN 0-608-02508-9.

13. Bi, Y.; Guan, J.; Bell, D. The combination of multiple classifiers using an evidential reasoning approach. Artif. Intell. 2008, 172, 1731-1751. [CrossRef]

14. Zhang, Y.J.; Deng, X.Y.; Wei, D.J.; Deng, Y. Assessment of E-Commerce security using AHP and evidential reasoning. Expert Syst. Appl. 2012, 39, 3611-3623. [CrossRef]

15. Dehe, B.; Bamford, D. Development, test and comparison of two Multiple Criteria Decision Analysis (MCDA) models: A case of healthcare infrastructure location. Expert Syst. Appl. 2015, 42, 6717-6727. [CrossRef]

16. Organisation for Economic Co-Operation and Development. Road Safety: Impact of New Technologies; Report; OECD: Paris, France, 2003.

17. Wardrop, J.G. Some theoretical aspects of road traffic research. Proc. Inst. Civ. Eng. 1952, 1, 325-378. [CrossRef]

18. Das-Friebel, A.; Wadhwa, N.; Sanil, M.; Kapoor, H.; Sharanya, V. Investigating Altruism and Selfishness through the Hypothetical Use of Superpowers. J. Hum. Psychol. 2017, 1, 1-28. [CrossRef]

19. Steijn, W.M.P.; Vedder, A. Privacy under Construction: A Developmental Perspective on Privacy Perception. Sci. Technol. Hum. Values 2015, 40, 615-637. [CrossRef]

20. Mattern, N.; Obst, M.; Schubert, R.; Wanielik, G. Simulative analysis of accuracy demands of co-operative localization in the COVEL project. In Proceedings of the 2011 IEEE Intelligent Vehicles Symposium (IV), Baden-Baden, Germany, 5-9 June 2011; pp. 516-521. [CrossRef]

21. Aparecido, L.; Boukerche, G.; Werner, R.; Loureiro, A. DRIVE: An efficient and robust data dissemination protocol for highway and urban vehicular ad hoc networks. Comput. Netw. 2014, 75, 381-394. [CrossRef]

22. Rakha, H.; Zang, W. Estimating traffic stream space-mean speed and reliability from dual and single loop detectors. Transp. Res. Rec. J. Transp. Res. Board 2005, 1925, 38-47. [CrossRef]

23. Soriguera, F.; Robusté, F. Estimation of traffic stream space-mean speed from time aggregations of double loop detector data. Transp. Res. Part C: Emerg. Technol. 2011, 19, 115-129. [CrossRef]

24. Martínez-Díaz, M.; Pérez, I. A simple algorithm for the estimation of road traffic space mean speeds from data available to most management centres. Transp. Res. Part B: Methodol. 2015, 75, 19-35. [CrossRef]

25. Turner, S.M.; Eisele, W.L.; Benz, R.J.; Holdener, D.J. Travel Time Data Collection Handbook; Research Report FHWA-PL-98-035; Federal Highway Administration, Office of Highway Information Management: Washington, DC, USA, 1998.

26. Soriguera, F.; Martínez-Díaz, M.; Pérez, I. Highway travel time information systems based on cumulative count curves and new tracking technologies. Transp. Res. Procedia 2016, 18, 44-50. [CrossRef]

27. Blank, G.; Dutton, W.H. Age and Trust in the Internet: The Centrality of Experience and Attitudes Toward Technology in Britain. Soc. Sci. Comput. Rev. 2012, 30, 135-151. [CrossRef]

28. Herrera, J.C.; Work, D.B.; Herring, R.; Ban, X.; Jacobson, Q.; Bayen, A.M. Evaluation of traffic data obtained via GPS-enabled mobile phones: The Mobile Century field experiment. Transp. Res. Part C: Emerg. Technol. 2010, 18, 568-583. [CrossRef]

29. Bachmann, C.; Abdulhai, B.; Roorda, M.J.; Moshiri, B. A comparative assessment of multi-sensor data fusion techniques for freeway traffic speed estimation using microsimulation modelling. Transp. Res. Part C: Emerg. Technol. 2013, 26, 33-48. [CrossRef]

30. Bieser, J.C.T.; Hilty, L.M. Assessing Indirect Environmental Effects of Information and Communication Technology (ICT): A Systematic Literature Review. Sustainability 2018, 10, 2662. [CrossRef]

31. Kwon, J.; Varaiya, P. Effectiveness of California's High Occupancy Vehicle (HOV) system. Transp. Res. Part C: Emerg. Technol. 2008, 16, 98-115. [CrossRef]

32. Menendez, M. An Analysis of HOV Lanes: Their Impact on Traffic. Ph.D. Thesis, Department of Civil and Environmental Engineering, University of California, Berkeley, CA, USA, 2006.

33. Menendez, M.; Daganzo, C.F. Effects of HOV Lanes on freeway bottlenecks. Transp. Res. Part B: Methodol. 2007, 41, 809-822. [CrossRef] 
34. Baldasano, J.M.; Gonçalves, M.; Soret, A.; Jiménez-Guerrero, P. Air pollution impacts of speed limitation measures in large cities: The need for improving traffic data in a metropolitan area. Atmos. Environ. 2010, 44, 2997-3006. [CrossRef]

35. Cascetta, E.; Punzo, V.; Sorvillo, R. Impact on vehicle speeds and pollutant emissions of a fully automated section speed control scheme on the Naples urban motorway. In Proceedings of the 89th Annual Meeting of the Transportation Research Board, Washington, DC, USA, 10-14 January 2010.

36. Soriguera, F.; Martínez, I.; Sala, M.; Menéndez, M. Effects of Low Speed Limits on Freeway Traffic Flow. Transp. Res. Part C: Emerg. Technol. 2017, 77, 257-274. [CrossRef]

37. Crump, C.; Cades, D.; Lester, B.; Reed, S.; Barakat, B.; Milan, L.; Young, D. Differing Perceptions of Advanced Driver Assistance Systems (ADAS). Sage J. 2016, 60, 861-865. [CrossRef]

38. Merat, N.; Lee, J.D. Preface to the Special Section on Human Factors and Automation in Vehicles. Designing Highly Automated Vehicles with the Driver in Mind. Hum. Factors 2012, 54, 681-686. [CrossRef] [PubMed]

39. Millard-Ball, A. Pedestrians, Autonomous Vehicles, and Cities. J. Plan. Educ. Res. 2016, 38, 6-12. [CrossRef]

40. Litman, T. Autonomous Vehicle Implementation Predictions: Implications for Transport Planning; Victoria Transport Policy Institute Press: Victoria, Canada, 2018.

41. Fagnant, D.J.; Kockelman, K. Preparing a nation for autonomous vehicles: Opportunities, barriers and policy recommendations. Transp. Res. Part A: Policy Pract. 2015, 77, 167-181. [CrossRef]

42. Papageorgiou, M. Freeway Traffic Management in the Era of VACS (Vehicle Automation and Communication Systems). In Proceedings of the IEEE 18th International Conference on Intelligent Transportation Systems "Smart Mobility for Safety and Sustainability", Canary Islands, Spain, 15-18 September 2015.

43. Diakaki, C.; Papageorgiou, M.; Papamichail, I.; Nikolos, I. Overview and analysis of Vehicle Automation and Communication Systems from a motorway traffic management perspective. Transp. Res. Part A: Policy Pract. 2015, 75, 147-165. [CrossRef]

44. Conference of European Directors of Roads (CEDR). Safe Distance between Vehicles. 2010. Available online: http:/ / www.cedr.eu/download/Publications/2010/e_Distance_between_vehicles.pdf (accessed on 25 March 2018).

45. Hyde, S.; Dalton, P.; Stevens, A. Attitudes to Autonomous Vehicles; Report PPR823; The TRL Academy: Berkshire, UK, 2017.

46. Guériau, M.; Billot, R.; El Faouzi, N.-E.; Monteil, J.; Armetta, F.; Hassas, S. How to assess the benefits of connected vehicles? A simulation framework for the design of cooperative traffic management strategies. Transp. Res. Part C: Emerg. Technol. 2016, 67, 266-279. [CrossRef]

47. Saeednia, M.; Menéndez, M. A Consensus-Based Algorithm for Truck Platooning. IEEE Trans. Intell. Transp. Syst. 2017, 18, 404-415. [CrossRef]

48. Nieuwenhuijsen, J.; de Almeida Correia, G.H.; Milakis, D.; van Arem, B.; van Daalen, E. Towards a quantitative method to analyze the long-term innovation diffusion of automated vehicles technology using system dynamics. Transp. Res. Part C: Emerg. Technol. 2018, 86, 300-327. [CrossRef]

49. Bonnefon, J.-F.; Azim, S.; Iyad, R. The Social Dilemma of Autonomous Vehicles. Science 2016, 352, $1573-1576$. [CrossRef] [PubMed]

50. Lin, P. Why Ethics Matters for Autonomous Cars. In Autonomous Driving; Maurer, M., Gerdes, J.C., Lenz, B., Winner, H., Eds.; Springer: Berlin, Germany, 2016; pp. 69-85, ISBN 978-3-662-48847-8.

51. JafariNaimi, N. Our Bodies in the Trolley's Path, or Why Self-driving Cars Must *Not* Be Programmed to Kill. Sci. Technol. Hum. Values 2017, 43, 302-323. [CrossRef]

52. German Federal Ministry of Transport and Digital Infrastructure. BMVI Ethics Commission. Available online: https://www.bmvi.de/SharedDocs/EN/publications/report-ethics-commission.pdf?_blob= publicationFile (accessed on 10 November 2018).

53. Recommendations to the Commission on Civil Law Rules on Robotics, "Mady Delvaux" European Parliament. 2017. Available online: http:/ / www.europarl.europa.eu/sides/getDoc.do?pubRef=- / /EP / /TEXT+REPORT+A8-2017-0005+0+DOC+XML+V0/ / EN (accessed on 26 February 2018).

54. Foot, P. The Problem of Abortion and the Doctrine of Double Effect. Oxf. Rev. 1967, 5, 5-15.

55. Doorn, N. Exploring Responsibility Rationales in Research and Development (R\&D). Sci. Technol. Hum. Values 2011, 37, 180-209. [CrossRef]

56. Schultz, B. The Happiness Philosophers: The Lives and Works of the Great Utilitarians; Princeton University Press: Princeton, NJ, USA, 2017; ISBN 9781400884957. 
57. Milakis, D.; van Arem, B.; van Wee, B. Policy and society related implications of automated driving: A review of literature and directions for future research. J. Intell. Transp. Syst. 2017, 21, 324-348. [CrossRef]

58. Mladenović, M.N. How Should We Drive Self-driving Vehicles? Anticipation and Collective Imagination in Planning Mobility Futures. In The Governance of Smart Transportation Systems. The Urban Book Series; Finger, M., Audouin, M., Eds.; Springer: Cham, Switzerland, 2019; pp. 103-122, ISBN 978-3-319-96525-3.

59. Stone, J.; Ashmore, D.; Scheurer, J.; Legacy, C.; Curits, C. Planning for Disruptive Transport Technologies: How Prepared Are Australian Transport Agencies? In Governance of the Smart Mobility Transition; Marsden, G., Reardon, L., Eds.; Emerald Insight: West Yorkshire, UK, 2018; pp. 123-137, ISBN 978-1-78754-320-1.

60. Shladover, S.E. The truth about self-driving cars. Sci. Am. 2016, 314, 52-57. [CrossRef] [PubMed]

61. Guo, F.; Yang, J.; Lu, J. The battery charging station location problem: Impact of users' range anxiety and distance convenience. Transp. Res. Part E: Log. Transp. Rev. 2018, 114, 1-18. [CrossRef]

62. Joint Research Centre (JRC). Sustainability Assessment of Road Transport Technologies; Joint Research Centre: Brussels, Belgium, 2012.

63. International Energy Agency. Global EV Outlook 2017. Two Million and Counting; Report; OECD: Paris, France, 2017.

64. Rietmann, N.; Lieven, T. A Comparison of Policy Measures Promoting Electric Vehicles in 20 Countries. In The Governance of Smart Transportation Systems. The Urban Book Series; Finger, M., Audouin, M., Eds.; Springer: Cham, Switzerland, 2019; pp. 125-145, ISBN 978-3-319-96525-3.

65. Ryghaug, M.; Skjølsvold, T.M. Nurturing a Regime Shift Toward Electro-mobility in Norway. In The Governance of Smart Transportation Systems. The Urban Book Series; Finger, M., Audouin, M., Eds.; Springer: Cham, Switzerland, 2019; pp. 147-165, ISBN 978-3-319-96525-3.

66. International Energy Agency. Energy Technology Perspectives 2017. Available online: http://www.iea.org/ etp/ (accessed on 1 March 2018).

67. Bloomberg New Energy Finance. Electric Vehicle Outlook 2017; Report; Bloomberg: New York, NY, USA, 2017.

68. Gaines, L. The future of automotive lithium-ion battery recycling: Charting a sustainable course. Sustain. Mater. Technol. 2014, 1, 2-7. [CrossRef]

69. Lane, B.W.; Dumortier, J.; Carley, S.; Siddiki, S.; Clark-Sutton, K.; Graham, J.D. All plug-in electric vehicles are not the same: Predictors of preference for a plug-in hybrid versus a battery-electric vehicle. Transp. Res. Part D: Transp. Environ. 2018, 65, 1-13. [CrossRef]

70. Dreier, D.; Silveira, S.; Khatiwada, D.; Fonseca, K.V.O.; Nieweglowski, R.; Schepanski, R. Well-to-Wheel analysis of fossil energy use and greenhouse gas emissions for conventional, hybrid-electric and plug-in hybrid-electric city buses in the BRT system in Curitiba, Brazil. Transp. Res. Part D: Transp. Environ. 2018, 58, 122-138. [CrossRef]

71. Bates, J.; Leibling, D. Spaced Out. Perspectives in Parking Policy; RAC Foundation: London, UK, 2012.

72. Cohen, B.; Kietzmann, J. Ride On! Mobility Business Models for the Sharing Economy. Organ. Environ. 2014, 27, 279-296. [CrossRef]

73. Ciari, F.; Bock, B.; Balmer, M. Modeling Station-Based and Free-Floating Carsharing Demand.Test Case Study for Berlin. Transp. Res. Rec. J. Transp. Res. Board 2014, 2416, 37-47. [CrossRef]

74. Heilig, M.; Mallig, N.; Schröder, O.; Kagerbauer, M.; Vortisch, P. Implementation of free-floating and station-based carsharing in an agent-based travel demand model. Travel Behav. Soc. 2018, 12, 151-158. [CrossRef]

75. Najmi, A.; Rey, D.; Rashidi, T.H. Novel dynamic formulations for real-time ride-sharing systems. Transp. Res. Part E: Log. Transp. Rev. 2017, 108, 122-140. [CrossRef]

76. Clewlow, R.; Mishra, G.S. Disruptive Transportation: The Adoption, Utilization, and Impacts of Ride-Hailing in the United States; Research Report UCD-ITS-RR-17-07; Institute of Transportation Studies, University of California: Davis, CA, USA, 2017.

77. Seign, R.; Bogenberger, K. Prescriptions for the Successful Diffusion of Carsharing with Electric Vehicles. In Proceedings of the Conference on Future Automotive Technology, Focus Electromobility, München, Germany, 18-19 March 2012.

78. Ohta, O.; Fujii, S.; Nishimura, Y.; Kozuka, M. Analysis of the Acceptance of Carsharing and Eco-Cars in Japan. Int. J. Sustain. Transp. 2013, 7, 449-467. [CrossRef]

79. Fleury, S.; Tom, A.; Jamet, E.; Colas-Maheux, E. What drives corporate carsharing acceptance? A French case study. Transp. Res. Part F: Traffic Psychol. Behav. 2017, 45, 218-227. [CrossRef] 
80. Dowling, R.; Maalsen, S.; Kent, J.L. Sharing as sociomaterial practice: Car sharing and the material reconstitution of automobility. Geoforum 2018, 88, 10-16. [CrossRef]

81. Heisserer, B.; Henrike, R. Capturing the consumption of distance? A practice-theoretical investigation of everyday travel. J. Consumer Cult. 2017, 17, 579-599. [CrossRef]

82. Belletti, F.; Bayen, A.M. Privacy-preserving MaaS fleet management. Transp. Res. Part C: Emerg. Technol. 2018, 94, 270-287. [CrossRef]

83. Li, Y. The Role of Public Authorities in the Development of Mobility-as-a-Service. In The Governance of Smart Transportation Systems. The Urban Book Series; Finger, M., Audouin, M., Eds.; Springer: Cham, Switzerland, 2019; pp. 229-245, ISBN 978-3-319-96525-3.

84. Smith, G.; Sarasini, S.; Karlsson, I.C.M.; Mukhtar-Landgren, D.; Sochor, J. Governing Mobility-as-a-Service: Insights from Sweden and Finland. In The Governance of Smart Transportation Systems. The Urban Book Series; Finger, M., Audouin, M., Eds.; Springer: Cham, Switzerland, 2019; pp. 169-188, ISBN 978-3-319-96525-3.

85. Pangbourne, K.; Stead, D.; Milakis, D. The Case of Mobility as a Service: A Critical Reflection on Challenges for Urban Transport and Mobility Governance. In Governance of the Smart Mobility Transition; Marsden, G., Reardon, L., Eds.; Emerald Insight: West Yorkshire, UK, 2018; pp. 33-48, ISBN 978-1-78754-320-1.

86. Santos, G. Sustainability and Shared Mobility Models. Sustainability 2018, 10, 3194. [CrossRef]

87. Akyelken, N.; Banister, D.; Givoni, M. The Sustainability of Shared Mobility in London: The Dilemma for Governance. Sustainability 2018, 10, 420. [CrossRef]

88. Stark Trek. Directed by Gene Roddenberry. 1968. USA. Television.

89. Blade Runner. Directed by Ridley Scott. 1982. USA. Cinema.

90. The World's First Flying Car. Available online: https://www.pal-v.com/ (accessed on 3 July 2018).

91. Rajashekara, K.; Wang, Q.; Matsuse, K. Flying Cars: Challenges and Propulsion Strategies. IEEE Electr. Mag. 2016, 4, 46-57. [CrossRef]

92. The Jetsons. Directed by William Hanna and Joseph Barbera. 1962. USA. Cinema.

93. Space, X. Hyperloop Alpha. 2013. Available online: http://www.spacex.com/sites/spacex/files/hyperloop_ alpha-20130812.pdf (accessed on 6 April 2018).

94. Zou, D. A look inside a new mode: Virgin Hyperloop One. Transp. Res. News 2018, 314, 15-19.

95. Mason, P. Scientist Lays out 5 Huge Problems with Elon Musk's Hyperloop. Interviewed in Dailycaller by Andrew Follet. 2016. Available online: http:/ / dailycaller.com/2016/07/26/scientist-lays-out-5-hugeproblems-with-elon-musks-hyperloop-video/ (accessed on 22 July 2018).

96. MIT Technology Review. The Unbelievable Reality of the Impossible Hyperloop. 10 May 2017. Available online: https: / / www.technologyreview.com/s / 601417/the-unbelievable-reality-of-the-impossible-hyperloop / (accessed on 22 July 2018).

97. Emerging Technologies. White Paper. Report of the San Diego Association of Governments. 2018. Available online: http:/ / www.sdforward.com/fwddoc/x-2018EmergingTechnologiesWhitePaper_kwa.pdf (accessed on 22 July 2018).

98. Shaheen, S.; Totte, H.; Stocker, A. Future of Mobility; The White Paper; UCConnect Press: Berkeley, CA, USA, 2018.

99. Page, E. The Man without a Body. The Sun, 25 March 1887.

100. Ren, J.; Xu, P.; Yong, H.; Zhang, L.; Liao, S.; Yin, J.; Liu, W.; Cai, W.; Yang, M.; Li, L.; et al. Ground-to-Satellite Quantum Teleportation; Cornell University Library: Ithaca, NY, USA, 2017.

101. Timmers, V.; Achten, P. Non-exhaust PM emissions from electric vehicles. Atmos. Environ. 2016, 134, $10-17$. [CrossRef]

102. Metclafe, T. The Terrafugia Transition Could End the Long Wait for Flying Cars. 2018. Available online: https:/ / www.nbcnews.com/mach/science/terrafugia-transition-means-long-wait-flying-cars-almostover-ncna919211 (accessed on 15 October 2018).

103. Anderson, R. Construction of “World's First” Hyperloop System to Begin in Abu Dhabi in Q3 2019. 2018. Available online: http:/ / gulfbusiness.com/construction-worlds-first-hyperloop-system-begin-abu-dhabi-q3/ (accessed on 24 October 2018).

104. McKinley, E. Hyperloop One Takes First Step on a Promising Test Road in America's Heartland. 2018. Available online: https:/ / www.cnbc.com/2018/10/18/hyperloop-one-takes-first-step-on-a-test-road-inamericas-heartland.html (accessed on 20 October 2018). 
105. García, F. Hyperloop: La Batalla Global por ser la Primera Empresa que lo Construya. 2018. Available online: http:/ / www.expansion.com/empresas/2018/08/11/5b6f0489e2704e1b6b8b45a9.html (accessed on 12 August 2018).

106. Hall, D. Teleportation: Will It Ever Be a Possibility? 2018. Available online: https:/ /www.theguardian.com/ technology /2018/jun/12/teleportation-will-it-ever-be-a-possibility (accessed on 1 August 2018).

107. Bennett, C.H.; Brassard, G.; Crepeau, C.; Jozsa, R.; Peres, A.; Wootters, W. Teleporting an Unknown Quantum State via Dual Classical and EPR Channels. Phys. Rev. Lett. 1993, 70, 1895-1899. [CrossRef] [PubMed]

108. Sudbury, T. Instant Teleportation. Nature 1993, 362, 586-587. [CrossRef]

109. Peterson, I. Science News. Available online: https:/ / www.sciencenews.org/author/ivars-peterson (accessed on 9 November 2018).

110. Gudowsky, N.; Sotoudeh, M.; Capari, L.; Wilfing, H. Transdisciplinary forward-looking agenda setting for age-friendly, human centered cities. Futures 2017, 90, 16-30. [CrossRef]

111. Knight, K.W.; Schor, J.B.; Jorgenson, A.K. Wealth Inequality and Carbon Emissions in High-income Countries. Soc. Curr. 2017, 4, 403-412. [CrossRef]

(C) 2018 by the authors. Licensee MDPI, Basel, Switzerland. This article is an open access article distributed under the terms and conditions of the Creative Commons Attribution (CC BY) license (http:/ / creativecommons.org/licenses/by/4.0/). 